\title{
Comparison of the instructional efficacy of an internet-based temporomandibular joint (TMJ) tutorial with a traditional seminar
}

IN BRIEF
Provides an insight into how computer
technology can be incorporated into
dental education.
Encourages readers to explore innovative
tools when providing dental education.
Demonstrates to readers (both students
and educational providers) how VLE may
be used effectively to enhance learning.

\author{
S. Al-Riyami, ${ }^{1}$ D. R. Moles, ${ }^{2}$ R. Leeson ${ }^{3}$ and S. J. Cunningham ${ }^{4}$
}

There has been growing interest in the use of virtual learning environments (VLEs) by universities over the past decade to supplement traditional teaching methods. In this study a tutorial providing information about the temporomandibular joint (TMJ), temporomandibular disorders and teaching of a thorough TMJ examination was developed on a VLE platform to enable students to enhance their examination and diagnostic skills. The success of this VLE tutorial was compared with conventional teaching by a cross-over trial. Thirty students were initially randomly allocated to one of two groups; Group 1 completed the VLE tutorial and Group 2 attended the face-to-face seminar in the first instance. The groups then crossed over and had the other method of teaching provided. The findings from the cross-over trial and the students' feedback indicated that no differences were found between either teaching modes, and both are equally effective at delivering information to students. In addition, the order in which the students received the teaching did not make a difference, but giving the teaching twice reinforced their knowledge. There is a strong case to be made for introducing clinical lectures on a VLE platform, and this form of e-learning is, in general, well perceived by new generations of students.

\section{INTRODUCTION}

There has been a shift in teaching methods in recent years. Traditionally, teaching was delivered in the workplace and further supplemented by textbook learning, but this model is now disappearing. ${ }^{1}$ Many institutions are incorporating e-learning in their syllabuses and information and communication technology (ICT) has had an impact on teaching and learning at all levels of dental education. ${ }^{2}$

There are many reasons for involving ICT in dental education and postgraduate education, in particular, exerts high demands on universities and teaching hospitals. $^{3}$ There are ever increasing needs and demands by dentists and other members of the dental team for continuing education

\footnotetext{
${ }^{1 *} \mathrm{PhD}$ student, Orthodontic Department, ${ }^{4}$ Senior Lecturer/Honorary Consultant, Orthodontic Unit, UCL Eastman Dental Institute, 256 Gray's Inn Road, London, WC1X 8LD; ${ }^{2}$ Professor of Oral Health Services Research, Peninsula Dental School, Research Way, Plymouth, Devon PL6 8BU; ${ }^{3}$ Senior Fellow of HNODS, Specialist Oral Surgeon, Eastman Dental Hospital, University College London Hospitals Foundation Trust, London *Correspondence to: Ms Salma Al-Riyami Email:s.alriyami@eastman.ucl.ac.uk
}

\section{Refereed Paper}

Accepted 30 April 2010

DOI: 10.1038/sj.bdj.2010.1085

${ }^{\circledR}$ British Dental Journal 2010; 209: 571-576 and teachers are under pressure to provide education and training at a time of dynamic growth in the demand for postgraduate and continuing education. ${ }^{2}$

The situation has been compounded by major institutional changes, with a drop in funding of 37\% per (UK higher education) full time student since $1989 .{ }^{4}$ In addition the number of academics and teaching staff is diminishing and, with the European Working Time Directive (EWTD) reducing the contact time with both trainers and peers, this may lead to the content in some educational programmes being compromised. Reduced training years at postgraduate level have diminished experiential exposure which makes formal skills training courses and simulation more important than ever. ${ }^{1}$

Virtual learning environments (VLEs) are an innovative method of delivering information and there is a growing interest in their use by schools, colleges and universities. VLEs make it possible for a course designer to present the components required for a course of education or teaching through a single consistent and intuitive interface. A survey carried out by the Joint Information Systems Committee (JISC) in 2005 indicated a high use of VLEs in all types of institutions, with 86\% of further education colleges, 97\% of pre-1992 universities and $90 \%$ of post-1992 universities reporting the use of at least one type of VLE. ${ }^{5}$

Anecdotal information suggests that many undergraduate and postgraduate dental students are unfamiliar with certain clinical procedures (for example, undertaking a thorough TMJ examination). There remains a need to provide this teaching and VLEs are a novel approach to conveying it. In dental education computer assisted learning and other electronic learning resources have been shown to be as effective as traditional methods of teaching. ${ }^{3}$ Thus the purpose of this study was to develop a TMJ module in order to enable students to enhance their examination and diagnostic skills and then to determine the success of this module compared with conventional teaching (a face-to-face seminar). The aims of this study were to assess:

1. Whether there was a difference in skills gained between students who were enrolled in the faceto-face seminar and those who learned through a VLE tutorial, by determining accuracy in examination and diagnosis 
2. Students' perceptions of VLE learning when compared with more traditional methods of teaching

3. The suitability of VLEs in delivering clinical/practical concepts to students.

\section{MATERIALS AND METHODS}

\section{Moodle VLE course}

A temporomandibular joint (TMJ) information course was developed for Moodle ${ }^{\mathrm{TM}}$ VLE. ${ }^{6}$ The content of this course included:

- An anatomy tutorial: a basic anatomy tutorial providing students with information on the structure and anatomy of the TMJ and associated muscles of mastication

- Information related to disorders of the TMJ: this guided users through conditions which may affect the TMJ as well as giving an overview of temporomandibular disorders (TMD) and how the classification of TMD has evolved

- Details of how to conduct a thorough TMJ examination: this included a multimedia presentation by one of the researchers (SA) which demonstrated how to conduct a thorough TMJ examination, highlighting the important signs to be recorded

- The Research Diagnostic Criteria for Temporomandibular Disorders (RDC/ TMD) Dworkin and LeResche, ${ }^{7}$ were also presented in a user friendly format.

\section{Face-to-face seminar}

A seminar and practical demonstration was prepared for the face-to-face teaching in a classroom setting with similar information and content and following exactly the same format as the Moodle course. One tutor (SA) prepared the content and delivered the seminar to all of the students, thus this ensured consistency in delivering the teaching. The seminar was of 50 minutes duration, of which the practical demonstration lasted 20 minutes and postgraduates had the opportunity to ask questions throughout. The students were given handouts of the RDC/TMD diagnostic criteria.

\section{Trial design}

A cross-over trial was conducted and 30 orthodontic graduate students were

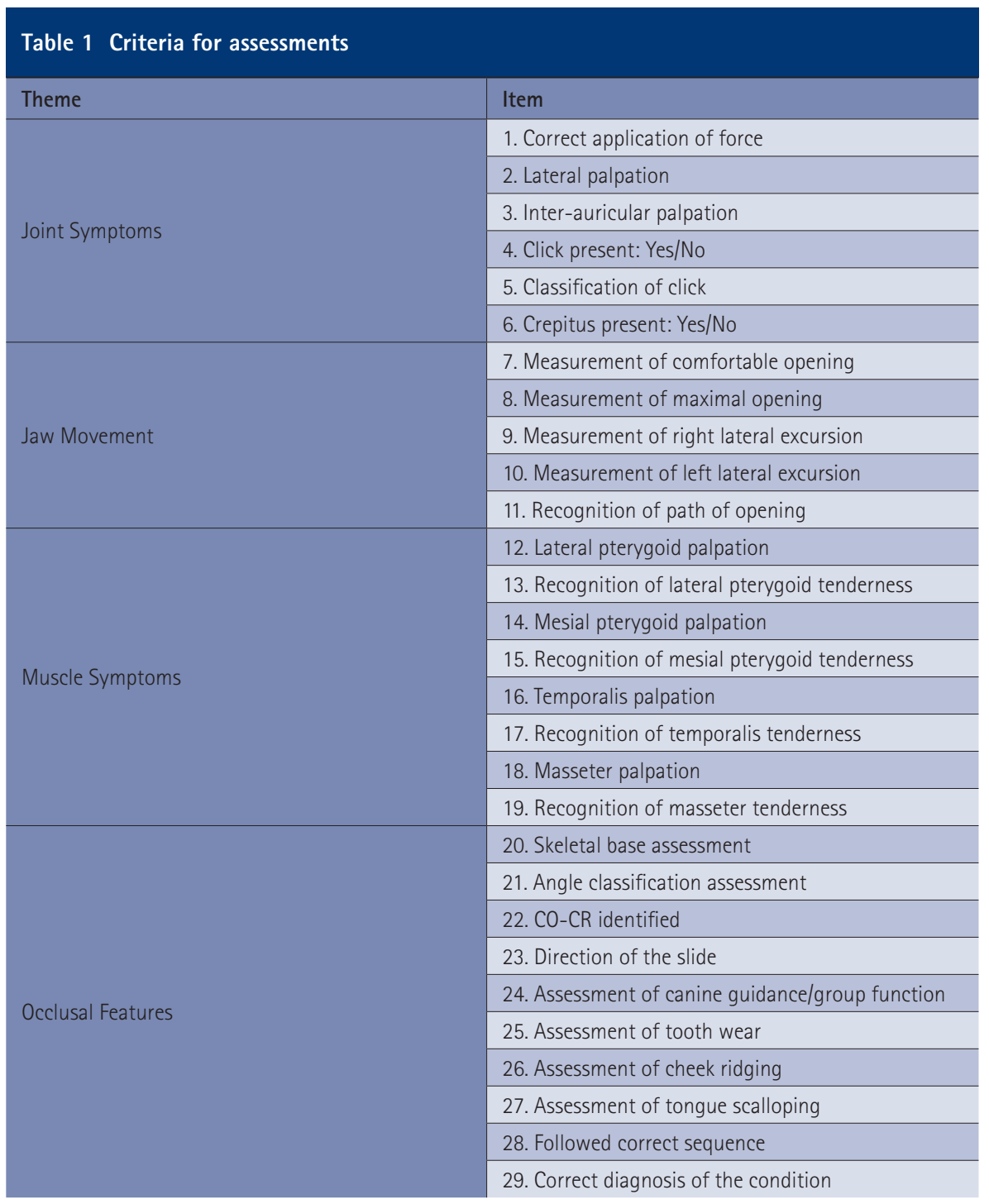

assigned by stratified random sampling to one of two groups:

i. Group 1: Moodle VLE tutorial followed by the face-to-face seminar ii. Group 2: Face-to-face seminar followed by Moodle VLE tutorial.

There were 23 female and seven male students in the study, with an age range of 26 to 36 years. Eighteen of the students were from the UK and 12 were from countries outside the UK/EU; initial questioning of the students revealed none of them had undergone any formal teaching in TMJ examination beyond a basic undergraduate level. None of them had significant experience of the use of VLEs.

There were 15 students per group and Group 1 was required to undertake the Moodle VLE tutorial initially. They were allowed to do this at their leisure but were given a two week deadline and users were tracked with the Moodle software to ensure they logged-on to the course. Group 2 was required to attend a face-to-face seminar on TMJ assessment and diagnosis, both groups had access to the same information and content, but the knowledge was conveyed using different methods.

At the end of this process students from both groups were required to examine a patient and diagnose their TMJ condition, these assessments were carried out within three weeks of the teaching episodes and were dependent on the student's schedule and availability. Students were assessed according to a checklist, with predefined criteria (Table 1). Volunteer subjects (12 auxiliary staff and non-clinical student volunteers) who presented with, and without, TMD signs and symptoms were made available for the students to conduct these examinations. The same assessor (SA) was present and observed the students during all examinations. The assessor had previously undergone a four-day calibration 


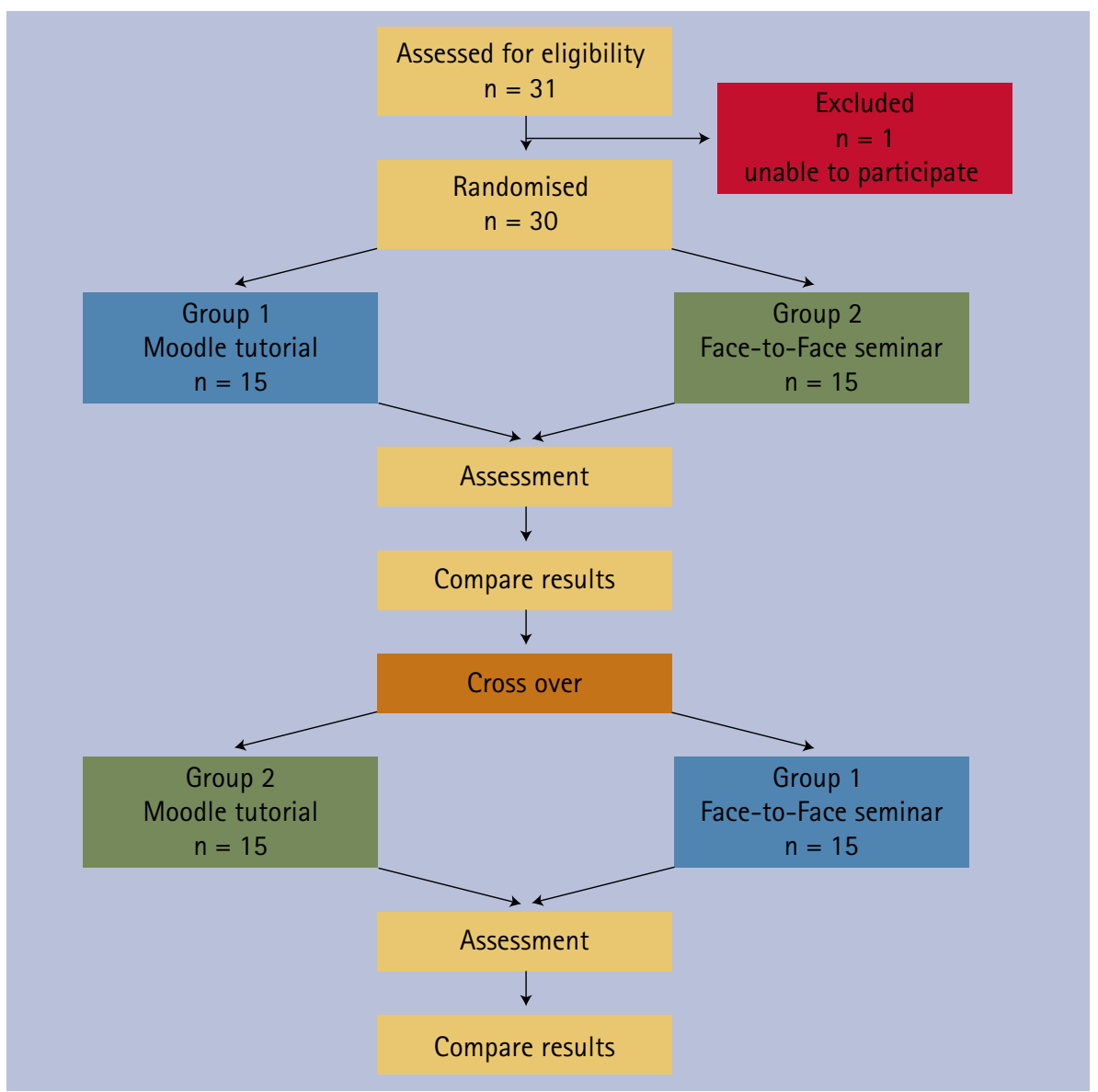

Fig. 1 Schematic diagram of the trial design

Table 2 Results for assessment after the first teaching episode

\begin{tabular}{|c|c|c|c|c|c|c|c|c|c|}
\hline \multirow[b]{2}{*}{ Theme } & \multirow[b]{2}{*}{ Group } & \multicolumn{7}{|c|}{ Results of the assessment } & \multirow{2}{*}{$\begin{array}{l}\mathrm{P} \\
\text { Value }\end{array}$} \\
\hline & & Mean & $\begin{array}{l}\text { Lower } \\
95 \% \mathrm{Cl}\end{array}$ & $\begin{array}{l}\text { Upper } \\
95 \% \mathrm{Cl}\end{array}$ & Std Dev & Median & Min & Max & \\
\hline \multirow{2}{*}{$\begin{array}{l}\text { Joint } \\
\text { Symptoms }\end{array}$} & 1 & 2.87 & 1.89 & 3.85 & 1.77 & 3 & 0 & 5 & \multirow{2}{*}{0.319} \\
\hline & 2 & 3.59 & 2.84 & 4.22 & 1.25 & 4 & 1 & 5 & \\
\hline \multirow{2}{*}{$\begin{array}{l}\text { Jaw } \\
\text { Movement }\end{array}$} & 1 & 3.33 & 2.38 & 4.28 & 1.72 & 4 & 0 & 5 & \multirow{2}{*}{0.553} \\
\hline & 2 & 3.07 & 2.19 & 3.94 & 1.58 & 3 & 0 & 5 & \\
\hline \multirow{2}{*}{$\begin{array}{l}\text { Muscle } \\
\text { Symptoms }\end{array}$} & 1 & 4.33 & 2.80 & 5.87 & 2.77 & 4 & 0 & 8 & \multirow{2}{*}{0.441} \\
\hline & 2 & 4.60 & 4.14 & 5.00 & 0.83 & 5 & 3 & 6 & \\
\hline \multirow{2}{*}{$\begin{array}{l}\text { Occlusal } \\
\text { Features }\end{array}$} & 1 & 3.33 & 2.38 & 4.28 & 1.72 & 4 & 0 & 5 & \multirow{2}{*}{0.553} \\
\hline & 2 & 3.07 & 2.19 & 3.94 & 1.58 & 3 & 0 & 5 & \\
\hline \multirow{2}{*}{ Total } & 1 & 13.87 & 10.37 & 17.36 & 6.31 & 11 & 4 & 23 & \multirow{2}{*}{0.787} \\
\hline & 2 & 14.27 & 12.18 & 16.35 & 3.77 & 15 & 9 & 19 & \\
\hline
\end{tabular}

course in TMJ examination procedures with an expert in this field, in addition the checklist and its criteria were discussed with a clinician experienced in facial pain management (RL).

A total of 29 items under four main themes were recorded on the checklist for the assessments. The assessor independently scored each student and had also previously examined all volunteer patients at the start of that session to determine their condition and set a 'gold standard' for the examination.
The results of the assessments for each group were compared, a washout period of two months was then allowed before the two groups crossed over (Fig. 1) and provided with the other mode of teaching. The students in Group 1 who had initially completed the Moodle tutorial had access to the VLE withdrawn, thus were unable to log-on and reinforce their knowledge.

The groups were assessed again within three weeks of the second phase of teaching and the results of the two groups were recorded for a second time. The students were also asked to anonymously complete a questionnaire based on their learning experiences and asked to rate both methods of teaching.

Statistical analysis was carried out using SPSS version 14, SPSS UK Ltd, Surrey, UK. The numerical results (obtained by summing the number of correctly completed individual assessment items) were assessed for normality using histograms and box and whisker plots. The data did not follow a normal distribution and the Mann-Whiney U test was applied to the independent variables, while the Wilcoxon Signed Ranks test was applied to the paired variables. The significance level for both tests was set at $\mathrm{P} \leq 0.05$.

\section{RESULTS}

The data were examined under four main themes (27 items):

1. Joint symptoms (items 1-6)

2. Jaw movement (items 7-11)

3. Muscle symptoms (items 12-19)

4. Occlusal features (items 20-27).

The final two items on the checklist 'Followed correct sequence of steps' and 'Diagnosis of patient's condition', however, were reported as individual findings.

\section{Assessment results after first teaching episode}

There were no significant differences observed between the assessment marks of the Group 1 and 2 students in any of the four themes or the 'total' score (Table 2). Both groups were equally able to diagnose the patients' TMJ conditions according to the RDC/TMD classification with 60\% of Group 1 and 73.3\% of Group $2(\mathrm{P}=0.439)$ being able to correctly classify the patients' TMJ status.

\section{Assessment results after cross-over and second teaching episode}

Table 3 summarises the results after the cross-over. These results mirrored the initial assessment findings and no significant differences were observed at the second assessment between Groups 1 and 2 for any of the four themes or for the total 29 items $(\mathrm{P}=0.416)$. In addition $80 \%$ of the students in both groups were able to give a correct diagnosis according to the RDC/ TMD criteria. 


\section{Group 1 - Moodle followed by face-to-face teaching}

When comparing the assessment results for Group 1 students before and after the cross-over (Table 4), a significant difference was observed for three of the themes, while a borderline significance was observed for Joint Symptoms $(\mathrm{P}=0.060)$. The results from the assessments indicated an improvement in all results at the second assessment. In addition the difference in assessment results for all 27 items was found to be highly significant $(\mathrm{P}=0.001)$, with students achieving better results after the second teaching episode (mean of 22.00 compared with 13.87).

With regards to following the correct sequence of steps and correct diagnosis of the patients' condition, there was a trend for the students to improve at the second assessment. Just over 50\% of the students followed the correct sequence of steps at the first assessment compared with $73.3 \%$ at the second assessment, and 40\% of the students diagnosed the patients' condition correctly at the first assessment compared with $80 \%$ at the second assessment. However, neither of these findings were found to be statistically significant ( $\mathrm{P}=0.375, \mathrm{P}=0.375$ respectively).

\section{Group 2 - Face-to-face}

\section{followed by Moodle teaching}

Table 5 presents the results of Group 2 before and after the cross-over, a significant difference was observed for the Occlusal Features theme between the first and second assessments $(\mathrm{P}=0.001)$. With regards to Joint Symptoms, the difference in assessment marks was of borderline significance $(P=0.053)$. In contrast, no significant difference was observed for the Muscle Symptoms or Jaw Movements themes, although there was a definite trend for the marks to improve. For the total marks achieved, there was a highly significant increase in the mean scores between the two assessments from 14.27 to $20.93(\mathrm{P}=0.001)$.

Forty percent of the students followed the correct sequence of steps at the first assessment compared with 73.3\% at the second assessment and this was found to be of borderline significance $(\mathrm{P}=0.063)$. There was also a small improvement in diagnosing the patients' condition with 73.3\% of students achieving the correct

\begin{tabular}{|c|c|c|c|c|c|c|c|c|c|}
\hline \multirow[b]{2}{*}{ Theme } & \multirow[b]{2}{*}{ Group } & \multicolumn{7}{|c|}{ Results of the assessment } & \multirow{2}{*}{$\begin{array}{l}\mathrm{P} \\
\text { Value }\end{array}$} \\
\hline & & Mean & $\begin{array}{l}\text { Lower } \\
95 \% \mathrm{Cl}\end{array}$ & $\begin{array}{l}\text { Upper } \\
95 \% \mathrm{Cl}\end{array}$ & Std Dev & Median & Min & Max & \\
\hline \multirow{2}{*}{$\begin{array}{l}\text { Joint } \\
\text { Symptoms }\end{array}$} & 1 & 3.93 & 3.14 & 4.73 & 1.44 & 4 & 1 & 6 & \multirow{2}{*}{0.153} \\
\hline & 2 & 4.53 & 3.99 & 5.08 & 0.99 & 5 & 2 & 6 & \\
\hline \multirow{2}{*}{$\begin{array}{l}\text { Jaw } \\
\text { Movement }\end{array}$} & 1 & 4.40 & 3.78 & 5.02 & 1.12 & 5 & 1 & 5 & \multirow{2}{*}{0.267} \\
\hline & 2 & 3.87 & 3.06 & 4.67 & 1.46 & 5 & 0 & 5 & \\
\hline \multirow{2}{*}{$\begin{array}{l}\text { Muscle } \\
\text { Symptoms }\end{array}$} & 1 & 6.20 & 5.17 & 7.23 & 1.86 & 6 & 4 & 8 & \multirow{2}{*}{0.081} \\
\hline & 2 & 5.13 & 4.18 & 6.09 & 1.73 & 5 & 3 & 8 & \\
\hline \multirow{2}{*}{$\begin{array}{l}\text { Occlusal } \\
\text { Features }\end{array}$} & 1 & 7.47 & 7.00 & 7.93 & 0.83 & 8 & 5 & 8 & \multirow{2}{*}{0.583} \\
\hline & 2 & 7.40 & 6.65 & 8.15 & 1.35 & 8 & 3 & 8 & \\
\hline \multirow{2}{*}{ Total } & 1 & 22.00 & 19.79 & 24.21 & 3.98 & 23 & 16 & 27 & \multirow{2}{*}{0.416} \\
\hline & 2 & 20.93 & 19.12 & 22.75 & 3.28 & 22 & 14 & 25 & \\
\hline
\end{tabular}

Table 4 Group 1 results comparing first and second assessment

\begin{tabular}{|c|c|c|c|c|c|c|c|c|c|}
\hline \multirow{2}{*}{ Theme } & & \multicolumn{7}{|c|}{ Results of the assessment } & \multirow{2}{*}{ P Value } \\
\hline & Time & Mean & $\begin{array}{l}\text { Lower } \\
95 \% \mathrm{Cl}\end{array}$ & $\begin{array}{l}\text { Upper } \\
95 \% \mathrm{Cl}\end{array}$ & $\begin{array}{l}\text { Std } \\
\text { Dev }\end{array}$ & Median & Min & Max & \\
\hline \multirow{2}{*}{$\begin{array}{l}\text { Joint } \\
\text { Symptoms }\end{array}$} & 1st & 2.87 & 1.89 & 3.85 & 1.77 & 3 & 0 & 5 & \multirow{2}{*}{0.060} \\
\hline & 2nd & 3.93 & 3.14 & 4.73 & 1.44 & 4 & 1 & 6 & \\
\hline \multirow{2}{*}{$\begin{array}{l}\text { Jaw } \\
\text { Movement }\end{array}$} & $1 \mathrm{st}$ & 3.33 & 2.38 & 4.28 & 1.72 & 4 & 0 & 5 & \multirow{2}{*}{0.012} \\
\hline & 2nd & 4.40 & 3.78 & 5.02 & 1.12 & 5 & 1 & 5 & \\
\hline \multirow{2}{*}{$\begin{array}{l}\text { Muscle } \\
\text { Symptoms }\end{array}$} & $1 \mathrm{st}$ & 4.33 & 2.80 & 5.87 & 2.77 & 4 & 0 & 8 & \multirow{2}{*}{0.018} \\
\hline & 2nd & 6.20 & 5.17 & 7.23 & 1.86 & 6 & 4 & 8 & \\
\hline \multirow{2}{*}{$\begin{array}{l}\text { Occlusal } \\
\text { Features }\end{array}$} & $1 \mathrm{st}$ & 3.33 & 2.38 & 4.28 & 1.72 & 4 & 0 & 5 & \multirow{2}{*}{0.001} \\
\hline & 2nd & 7.47 & 7.00 & 7.93 & 0.83 & 8 & 5 & 8 & \\
\hline \multirow{2}{*}{ Total } & $1 s t$ & 13.87 & 10.37 & 17.36 & 6.31 & 11 & 4 & 23 & \multirow{2}{*}{0.001} \\
\hline & 2nd & 22.00 & 19.79 & 24.21 & 3.98 & 23 & 16 & 27 & \\
\hline
\end{tabular}

Table 5 Group 2 results comparing first and second assessment

\begin{tabular}{|c|c|c|c|c|c|c|c|c|c|}
\hline \multirow[b]{2}{*}{ Theme } & \multirow[b]{2}{*}{ Time } & \multicolumn{7}{|c|}{ Results of the assessment } & \multirow[b]{2}{*}{ P Value } \\
\hline & & Mean & $\begin{array}{l}\text { Lower } \\
95 \% \mathrm{Cl}\end{array}$ & $\begin{array}{l}\text { Upper } \\
95 \% \mathrm{Cl}\end{array}$ & Std Dev & Median & Min & $\operatorname{Max}$ & \\
\hline \multirow{2}{*}{$\begin{array}{l}\text { Joint } \\
\text { Symptoms }\end{array}$} & 1st & 3.59 & 2.84 & 4.22 & 1.25 & 4 & 1 & 5 & \multirow{2}{*}{0.053} \\
\hline & 2nd & 4.53 & 3.99 & 5.08 & 0.99 & 5 & 2 & 6 & \\
\hline \multirow{2}{*}{$\begin{array}{l}\text { Jaw } \\
\text { Movement }\end{array}$} & 1st & 3.07 & 2.19 & 3.94 & 1.58 & 3 & 0 & 5 & \multirow{2}{*}{0.190} \\
\hline & 2nd & 3.87 & 3.06 & 4.67 & 1.46 & 5 & 0 & 5 & \\
\hline \multirow{2}{*}{$\begin{array}{l}\text { Muscle } \\
\text { Symptoms }\end{array}$} & $1 \mathrm{st}$ & 4.60 & 4.14 & 5.00 & 0.83 & 5 & 3 & 6 & \multirow{2}{*}{0.332} \\
\hline & 2nd & 5.13 & 4.18 & 6.09 & 1.73 & 5 & 3 & 8 & \\
\hline \multirow{2}{*}{$\begin{array}{l}\text { Occlusal } \\
\text { Features }\end{array}$} & 1st & 3.07 & 2.19 & 3.94 & 1.58 & 3 & 0 & 5 & \multirow{2}{*}{0.001} \\
\hline & 2nd & 7.40 & 6.65 & 8.15 & 1.35 & 8 & 3 & 8 & \\
\hline \multirow{2}{*}{ Total } & 1st & 14.27 & 12.18 & 16.35 & 3.77 & 15 & 9 & 19 & \multirow{2}{*}{0.001} \\
\hline & 2nd & 20.93 & 19.12 & 22.75 & 3.28 & 22 & 14 & 25 & \\
\hline
\end{tabular}

diagnosis at the first assessment compared with $80.0 \%$ at the second assessment, however, this was not statistically significant.

\section{FEEDBACK QUESTIONNAIRE FINDINGS}

Although the students were asked 21 questions, the key findings related to course preference are presented.

\section{Question 1 - Which course} would you recommend?

When asked which course they would recommend, 16 of the 30 students said they would recommend the Moodle tutorial compared with the 14 for the face-to-face seminar. 
Question 2 - How would you rate the Moodle tutorial/face-to-face seminar on a scale of 1-10?

The ratings for both courses were varied. None of the students gave the courses very low ratings (1 and 2), 18 students rated the Moodle tutorial very highly giving scores of $\geq 8$, and similar numbers $(n=15)$ gave the face-to-face seminar scores of $\geq 8$.

\section{Question 3 - If you could choose one course to enrol on which would it be?}

Sixteen students chose the Moodle tutorial, compared with the 14 who chose the faceto-face seminar.

\section{DISCUSSION}

\section{Developing the Moodle course}

Although the TMJ Information Course was developed in an orthodontic department, the topic covers many disciplines and has relevance for prosthodontics, oral and maxillofacial surgery, facial pain units and general dental practitioners; as such it is a useful learning tool for many people. As the responsibility for providing this teaching is shared among various departments, it can sometimes be overlooked and creating this course provides a central point for accessing information.

There are undoubtedly benefits associated with providing teaching on a VLE platform, however, the development stage of this study highlighted certain difficulties. Some students wanting to access the course from their home computers had log-in difficulties associated with the universities networking capabilities and in certain instances there were web-browser incompatibilities, especially with respect to watching the TMJ examination video. Internet band-width affected the ability of some students to efficiently complete the course from home, and when a student experienced any number of the above problems they were less likely to persevere and log-on again.

For the Moodle tutorial, it was possible to track user activity and identify the elements a student had completed, however, it was not possible to determine the length of time each student spent on the content. Thus if a student skimmed through a tutorial or read it in-depth the projected usage would be the same. Nonetheless, traditional teaching methods do not overcome this obstacle, and even in a lecture, it is highly likely that some of those present may be preoccupied elsewhere!

The Moodle course incorporated a discussion board and forum for users to discuss the topic with each other and to provide interactivity between the students and the tutor. Unfortunately, however, this feature of Moodle was underutilised in this study.

\section{Cross-over trial}

\section{Assessment results after}

first teaching episode

No significant differences were found between the performance of Group 1 and 2 students, suggesting that both teaching modes are equally valuable educational tools. Either mode of teaching was equally effective at delivering the information to the students and it appeared that both groups acquired similar skill sets in conducting a TMJ examination. With respect to diagnosis, $60.6 \%$ of the students in Group 1 and 73.3\% in Group 2 accurately diagnosed the patient's condition and there was no statistically significant difference between groups ( $\mathrm{P}=0.439$ ). As such the type of teaching the students received did not appear to influence their ability to diagnose temporomandibular joint disorders. Others looking at the effectiveness of online learning have come to the same conclusion and found that an online continuing medical education (CME) module produced objectively measured changes in the behaviour of the physicians, as well as sustained gains in their knowledge that were comparable with those from a traditional CME group. ${ }^{8}$

\section{Assessment results after the cross over and second teaching episode}

At the second assessment there was no significant difference between the two groups for any of the four themes and it can be deduced that, even after the cross-over, both teaching modalities were equally effective and there were no significant differences in the skills acquired by the students. In addition, both groups performed equally well in the diagnosis of TMD (80\% diagnosed the TMJ condition correctly in both groups).

It does not appear that the order in which the postgraduates had received the teaching made a difference, whether a student had the Moodle tutorial followed by a face-to-face seminar or vice versa: the students performed similarly. The ability of e-learning to promote educational objectives is considerable, thus provided it is well designed and executed, online or web based courses can be equally effective in conveying information, and influencing changes to practice. ${ }^{8}$

\section{Group 1}

The results before and after the cross-over showed a significant difference for three of the themes (Jaw Movement, Muscle Symptoms and Occlusal Features) with the students' performance improving after the second teaching episode. The fourth theme (Joint Symptoms) showed borderline significance, again with a tendency for improvement at the second assessment. When all 29 items were combined, students were found to have higher marks at the second assessment and this was highly significant. As such, although Moodle or face-to-face teaching are both effective, having the teaching twice appeared to reinforce the students' knowledge and there was a significant improvement in their performances at the second assessment. Clearly students may have performed better the second time because they knew what to expect, thus improvements in the students performance may also be credited to the assessment procedure itself and not solely to double teaching. Assessments are often implemented to improve learning practices, stimulating attention and retrieval processes. ${ }^{9}$

\section{Group 2}

Significant differences were found for two of the themes (Joint Symptoms and Occlusal Features). The remaining two themes showed no significant differences, however the mean results for these two themes showed an improvement between the first and second assessments. This lack of significant findings may be due to the relatively small sample size in this trial and warrants further investigation.

For all 29 items, a highly significant difference was found, suggesting that the total assessment results were higher after the cross-over and the second episode of teaching. This is in line with what may be expected educationally; repetition is a common pedagogy technique which helps to stimulate the memory and motivates awareness, thus for quality learning one should 
consciously design repetitive engagement into courses and daily teaching. ${ }^{10}$

Repeated teaching of the same topic is more effective than teaching a topic once and it is not uncommon in educational environments to provide revision lectures and tutorials. Having a lecture or other form of teaching on a VLE can be considered an invaluable educational tool, as it provides the resources for revision, without the need to schedule a live lecture, thus is a more efficient use of academic time.

\section{Feedback}

When asked whether they would recommend the course, the distribution of students who would recommend the Moodle tutorial was similar to those who would recommend the face-to-face seminar and the responses were positive, with the majority answering 'Agree' or' Strongly agree'. When asked how they would rate the course 18 students gave the Moodle course a ranking of 8 and above, and a similar figure of 15 students gave the face-to-face seminar a ranking of 8 and above. The findings reflect previous studies which have reported that VLEs receive positive feedback from students. ${ }^{2}$

Feedback from the questionnaire also indicated that both courses were well received by the students and there is certainly a place for both in dental education. Students could theoretically be given the option of which course they enrol on and some may find online learning beneficial due to travel constraints and clinical restrictions. However, it should be noted that a study looking at VLE use in dentistry found that some peripheral trainees placed a high value on face-toface teaching and were prepared to travel in order to attend this form of teaching. ${ }^{11}$ Indeed students have frequently cited fear of isolation and lack of a community environment as a shortcoming of VLEs. ${ }^{12}$

The findings from the cross-over trial and the feedback indicate that there is a strong case to be made for introducing clinical lectures on a VLE platform and this form of e-learning is, in general, well received by new generations of students. VLEs should not completely replace traditional lectures and tutorials as these are also very well regarded by students. The solution to this conundrum is the concept of blended learning which combines online components of study with face-to-face classroom based interaction. Ruiz et al. ${ }^{13}$ recommended the integration of e-learning into curricula using a blended learning format rather than moving entirely to computer-based programmes. To maximise the outcomes of an educational process, VLEs should be aligned with the process of the course and not the other way around. As such VLEs should be adaptable to meet a course's needs and traditional methods are still used where they are most effective such as in some one-to-one clinical teaching scenarios. ${ }^{14}$ VLEs may also prove useful and relevant to GDPs to be run alongside continuing professional development (CPD) courses. CPD courses provide face-to-face teaching, but GDPs do not usually have the opportunity for revision lectures, thus VLEs can be used as a revision tool.

A recent study by Carbonaro et al. ${ }^{15}$ looked at the effects and benefits of a newly developed blended learning course for health science students and compared this with the existing face-to-face format. As with the current study, students were assigned into either of two groups and completed a post-course Objective Structured Clinical Examination (OSCE). The results were similar to this study and no differences were found between the two groups in achieving team process skills; both the blended learning group and the face-to-face groups demonstrated similar results. Interestingly, Carbonaro et al..$^{15}$ found significant differences between the groups on the perceived positive achievement of the course learning objectives and the blended learning group were more convinced that their course provided them this. The novelty of using technology in the classroom may have played a role in the positive responses, ${ }^{16}$ and could explain the encouraging feedback received by some students in the current study.

\section{CONCLUSION}

1. There were no differences in skills gained between students who were enrolled in the seminar and those who learned through a VLE tutorial, with regards to accuracy in TMJ examination and diagnosis

2. Students had positive perceptions of VLE learning and the feedback to this mode of teaching was comparable with more traditional methods of teaching

3. VLEs are suitable for delivering clinical/ practical demonstration concepts. They may also be particularly useful as a follow-up or revision tool, for example inclusion of VLEs alongside CPD courses in order to reinforce the information at a later stage.

Blended learning and incorporating VLEs into dental education appears to be an important development and, provided courses are appropriately designed, they can be instrumental in encouraging effective learning. The uptake of information and the skills that are attained by students are comparable with those expected from traditional teaching methods. There are the added benefits of easy access 'anytime anywhere' and the conservation of academic resources in what is already an overwhelmed profession.

1. Larvin M. E-learning in surgical education and training. ANZ J Surg 2009; 79: 133-137.

2. Eaton K A, Reynolds P A. Continuing professional development and ICT: target practice. Br Dent J 2008; 205: 89-93.

3. Ireland A J, Smith A S, Alder D M, Sandy J R, Chadwick S M. Building a learning community on-line: the first step towards a national virtual learning environment in orthodontics. J Orthod 2005; 32: 214-219.

4. Ellaway R, Dewhurst $D$, Cumming A. Managing and supporting medical education with a virtual learning environment: the Edinburgh Electronic Medical Curriculum. Med Teach 2003; 25: 372-380.

5. Joint Information Systems Committee (JISC) [Online]. Available from http://www.jiscinfonet. ac.uk/InfoKits/effective-use-of-VLEs/intro-to-VLES/ introtovle-intro/index_html [Accessed 12/10/2009]

6. Moodle [Online]. Available from http://moodle.org [Accessed 12/10/2009].

7. Dworkin S F, LeResche L. Research diagnostic criteria for temporomandibular disorders: review, criteria, examinations and specifications, critique. J Craniomandib Disord 1992; 6: 301-355.

8. Fordis M, King J E, Ballantyne C M, Jones P H et al. Comparison of the instructional efficacy of Internet-based CME with live interactive CME workshops: a randomized controlled trial. JAMA 2005; 294: 1043-1051

9. Shepard E, Godwin J. Assessments through the learning process [Online]. Available from http:// www.oln.org/ILT/pdf/Assessments-Ryan.pdf. [Accessed 12/10/2009]

10. Bruner, Robert F. Repetition is the first principle of all learning [Online]. 2001. Available from SSRN: http:// ssrn.com/abstract=224340 [Accessed 12/10/2009].

11. Mulgrew B, Drage K, Gardiner P, Ireland T, Sandy J R. An evaluation of the effects of a web-based modular teaching programme, housed within a virtual learning environment on orthodontic training for specialist registrars. J Orthod 2009; 36: 167-176.

12. Shah $R$, Cunningham S J. Implementation of the virtual learning environment into a UK orthodontic training programme: the postgraduate and lecture perspective. Eur J Dent Educ 2009; 13: 223-232.

13. Ruiz J G, Mintzer M J, Leipzig R M. The impact of E-learning in medical education. Acad Med 2006; 81: 207-212.

14. Biggs J. Teaching for quality learning. Milton Keynes: Open University Press, 1999.

15. Carbonaro $M$, King $S$, Taylor $E_{\text {, Satzinger }}$, Snart $F_{\text {, }}$ Drummond J. Integration of e-learning technologies in an interprofessional health science course. Med Teach 2008; 30: 25-33.

16. Niemiec $R H$, Walberg H J. Comparative effects of computer assisted instruction: a synthesis of reviews. J Educ Comput Res 1987; 3: 19-37. 